\title{
OS KAMIKAZES E O ENSINO DE HISTÓRIA NO MANGÁ “ZERO ETERNO”
}

\author{
THE KAMIKAZES AND HISTORY TEACHING IN MANGA “ZERO ETERNO”
}

\author{
Mônica Rodrigues Suminami ${ }^{1}$ \\ Tânia Regina Zimmermann ${ }^{2}$ \\ Márcia Maria de Medeiros ${ }^{3}$
}

\begin{abstract}
Resumo
A pesquisa analisa os cinco volumes do mangá Zero Eterno, cujo tema central são os pilotos kamikazes. O conjunto desses mangás desperta a curiosidade sobre o tema no ensino de história contemporânea, sobretudo daqueles que se interessam pelo evento da Segunda Guerra Mundial, pelo peculiar esquadrão suicida japonês e por algumas batalhas entre os japoneses e os norte-americanos no Pacífico. A pesquisa, através de uma revisão bibliográfica sobre o contexto histórico do século $\mathrm{XX}$, procura novos olhares sobre a atuação dos kamikazes representada nesses mangás. $\mathrm{O}$ uso das histórias em quadrinhos objetiva inserir novas tendências do ensino e pesquisa, ou seja, outras possibilidades de se narrar e resgatar uma história tão distante e também esquecida. Desta forma, procurou-se demonstrar que o mangá, tido como uma história em quadrinhos, pode ser utilizado como mecanismo de assimilação de conhecimentos formulados pelo professor para o alunado, com base numa metodologia que facilita a difusão de conhecimentos, pois inova na prática do ensino de História. Assim sendo, atrelando os eventos históricos ocorridos com outras possibilidades didáticas na difusão do ensino, verificou-se que tais fatos que foram vividos pelos ex-combatentes sobreviventes, adquiriram outros contornos, olhares e causas pelas quais se lutou.
\end{abstract}

Palavras-chave: Mangá. kamikazes. Segunda Guerra Mundial. Japão.

\begin{abstract}
The research analyzes the five volumes of manga Zero Eterno, whose central theme is the kamikaze pilots. All these mangas arouses curiosity on the subject in the teaching of contemporary history, especially those who are interested in World War II event, the peculiar Japanese suicide squad and some battles between Japanese and Americans in the Pacific. The research, through a literature review on the historical context of the twentieth century, looking for new perspectives on the performance of those represented kamikaze manga. These comics aim to introduce new trends in teaching and research, or other possibilities of narrating and rescue a story so far and forgotten. Thus, he tried to demonstrate that the manga, seen as a comic, can be used as knowledge assimilation mechanism formulated by the teacher to the

\footnotetext{
${ }^{1}$ Mestranda em Educação pela Universidade Estadual de Mato Grosso do Sul (Uems/2014), especialista em Direito Processual pela Universidade do Sul de Santa Catarina (Unisul), especialista em Direito Tributário pela Universidade do Sul de Santa Catarina (Unisul). É bacharela em Direito pela Universidade Estadual de Mato Grosso do Sul (Uems/2006). E-mail: monica_suminami@hotmail.com

${ }^{2}$ A autora é doutora em História pela Universidade Federal de Santa Catarina (2010). Atualmente é professora titular da Universidade Estadual de Mato Grosso do Sul. E-mail: tania22@uems.br

3 A autora é doutora em Letras pela Universidade Estadual de Londrina (2006). Professora adjunta da Universidade Estadual de Mato Grosso do Sul (UEMS). E-mail: maeve35@ hotmail.com
} 
student body, based on a methodology that facilitates the dissemination of knowledge, for innovation in practice History teaching. Thus, linking historical events with the teaching facility in the spread of education, it found that such facts that have come to be experienced by veterans survivors, acquired other contours, looks and causes for which he fought.

Keywords: Manga. Kamikazes. Second World War. Japan.

\section{INTRODUÇÃO}

O que chamamos realidade é apenas o senso comum de
nossa cultura. Ignorar outras culturas é estar cego para
outras realidades (ALAN MOORE).

As práticas de ensino nas salas de aula, atualmente, têm se familiarizado com percalços e incertezas, na medida em que o saber docente, embora constituído pelo conhecimento pedagógico, não tem encontrado como destinatário final o aluno interessado na transmissão de valores por meio do aprendizado. Neste sentido, a construção da identidade ${ }^{4}$ do aluno, por intermédio dessa transmissão de valores tem-se prejudicado, tanto que novas reformulações nos métodos de ensino-aprendizagem começaram a serem abordadas como alternativas viáveis para o sucesso na captação de valores culturais e ideológicos por parte dos alunos.

Tais reformulações se baseiam em oferecer "novos ares" aos alunos, ou melhor, motivações de aprendizagem para que essa captação de conhecimentos se torne frutífera e satisfatória. De ver-se, que a história em quadrinhos se tem constituído como um recurso didático para que o ensino se renove e se enriqueça, fazendo com que o leque de formas de ensinar disponíveis ao professorado detenha uma multiplicidade de temas a serem abordados, facilitando o entendimento de saberes, como a cidadania, valores culturais e identitários.

Por intermédio de uma linguagem informal, de onomatopéias e balões que extravasam às páginas, dando voz aos personagens, o mangá (que também pode ser conhecido como história em quadrinhos), consegue revitalizar o ensino de história, mais precisamente da história contemporânea. Assim, por meio do mangá "Zero Eterno", onde é exposto uma narrativa a respeito da vida dos kamikazes japoneses que se enveredavam como alvos, em

\footnotetext{
${ }^{4}$ Aqui, a identidade faz menção ao que se entende como "cultura como identidade". Terry Eagleton (2011) antevê a possibilidade da cultura se ligar ao próprio indivíduo, conseguindo, inclusive, revelar o seu espírito, na medida em que este desenvolve aquela sensação de pertencimento a um lugar.
} 
ataques "suicidas" durante a segunda guerra mundial. Fundamentalmente, a problemática se evidencia a respeito da ideologia por parte desses pilotos, trazendo à tona a discussão a respeito da motivação desses ataques, ou seja, se tais pilotos seriam ousados, suicidas ou, simplesmente, respeitavam uma ordem hierarquicamente superior.

\section{DO MANGÁ “ZERO ETERNO”: NARRATIVAS E APELO HISTÓRICO}

Segundo Coggiola (1995) a Segunda Grande Guerra (1939-45) contou com 60 milhões de homens em armas, 50 milhões de mortes (a maioria na população civil) como resultado nos combates e por fim o total de aproximadamente 80 milhões de pessoas vítimas contando com pessoas que morreram por fome e doença. No período, estes representavam aproximadamente, $4 \%$ da população mundial em menos de 5 anos de guerra.

Esses números expressam a quantidade dos massacres, sobretudo da população civil. Mortes estas sob responsabilidade dos principais protagonistas da guerra, inclusive os defensores da liberdade e da democracia. À exemplo, citamos os bombardeios sobre a cidade alemã de Dresden, ou das duas bombas atômicas lançadas sobre Nagasaki e Hiroshima (quando a capitulação do Japão era questão de poucas horas). Segundo a opinião de Winston Churchill, “[...] seria um erro supor que o destino do Japão foi decidido pela bomba atômica. A derrota do Celeste Império já estava assegurada antes de ser lançada a primeira bomba". (OLYMPIO, 1995, p. 107).

Osvaldo Coggiola observa que o uso e armas atômicas também possuíam um conteúdo racista em relação aos japoneses. Ainda advoga que:

De fato, o racismo não foi patrimônio exclusivo dos nazistas, assim como as experiências científicas do Dr. Mengele em Auschwitz (ou de seu equivalente japonês, a Unidade 731 do norte da China). Os Estados Unidos acabam de reconhecer oficialmente ter submetido a provas nucleares mais de 600 pessoas no seu próprio território durante a Segunda Guerra, incluindo dezoito norte-americanos que morreram depois de ter recebido injeções de plutônio. O racismo e a barbárie foram multidirecionais. (COGGIOLA, 1995, p. 01).

Conforme Coggiola, para explicar as causas e o desfecho dessa guerra, não basta referir-se aos objetivos estratégicos nacionais dos países ou blocos envolvidos. Neste sentido, vale-se dos aportes de Karl von Clausewitz para o qual "a guerra é a continuação da política 
por outros meios", não reduzindo a política e a guerra à expressão dos interesses dos Estados nacionais:

\begin{abstract}
Afirmamos que a guerra não é um domínio das artes ou das ciências, mas um elemento do tecido social. Constitui um conflito de grandes interesses solucionado de maneira sangrenta, o que a diferencia de todos os outros conflitos. Antes de comparar a guerra com uma arte qualquer, caberia fazê-lo com o comércio, que é também um conflito de atividades e interesses humanos, e inclusive se assemelha muito à política, que por sua vez pode ser considerada como uma espécie de comércio em grande escala. A política é a matriz em que se desenvolve a guerra. (COGGIOLA, 1995, p. 02).
\end{abstract}

Coggiola ainda observa o difícil quadro de possíveis alianças antes da Segunda Guerra, mas salienta que a participação dos Estados Unidos não foi preventiva, mas central até o ataque japonês a Pearl Harbour. A política americana com relação ao Japão e a Alemanha eram ambíguas, e isso desmente a visão ideológica retrospectiva de uma guerra da democracia contra o fascismo. (COGGIOLA, 1995, p. 3).

Hobsbawm (1995) considera que a Segunda Guerra Mundial foi um conflito imperialista devido as contradições nacionais, mas também contrarrevolucionário pois a destruição da União das Repúblicas Socialistas Soviéticas (URSS) poderia interromper o processo revolucionário iniciado em 1917, evitando que o exemplo se espalhasse para outros países.

Neste sentido, Coggiola (1995) aponta para a evidência explícita do caráter contrarrevolucionário do caminho político que levaria à Segunda Guerra Mundial:

\footnotetext{
[...] no fato de que a aliança Alemanha-Itália-Japão, configurada na década de 30 (e que seria um dos blocos do conflito), autodenominou-se Pacto AntiKomintern, isto é, explicitamente dirigido a conter a 'expansão mundial do comunismo'. O outro aspecto está no fato de que a economia armamentista, posta em pé na década prévia à Guerra (em primeiro lugar nas potências totalitárias), foi a única via de saída para a crise em que a economia capitalista mundial tinha entrado em 1929. (COGGIOLA, 1995, p. 5).
}

Ainda segundo este autor, a Segunda Guerra foi umas das soluções para a crise econômica. As relações internacionais tornaram-se tensas ao longo da década de 1930. As barreiras protecionistas visando preservar os mercados e a necessidade de expansão das potências do Eixo levaram ao acirramento das tensões interimperialistas.

Segundo Gabriela Rodrigues (2000) a Segunda Guerra Mundial, começou na Ásia em 1937 e atingiu de forma diferenciada as diversas subregiões do continente asiático. 
O Japão da Revolução Meiji alijou do poder político o regime considerado feudal do Xogunato Tokugawa. Nos começos desse processo, o país apresentava um isolamento do cenário internacional devido aos efeitos dos Tratados Infames de comércio que comprometiam o desenvolvimento econômico. Após 1868, uma nova elite assumiu o país prometendo reformas econômicas, aceleração da industrialização e a constituição de uma armada forte. Esse processo foi conduzido pelo zaibatsu, que eram grandes monopólios econômicos. Com isso, o Japão expandiu-se pela Ásia guerreando com a China em 1894 e com a Rússia em 1904 marcando algumas vantagens territoriais e econômicas.

Durante a I Guerra Mundial, o Japão não teve participação expressiva, mas declarou guerra a Alemanha e invadiu militarmente a China ocupando possessões da Alemanha. Com o final da guerra, o Japão enviou suas pretensões ao Tratado de Versalhes e a Conferência de Washington. Estas foram recusadas e assim demonstrava-se a rivalidade entre EUA e Japão. Para os japoneses um acordo com os norte-americanos representava sua subordinação (RODRIGUES, 2000). Após a I Guerra Mundial, o Japão obteve alguns benefícios como o fornecimento de produtos para a Europa desabastecida.

O Japão intencionava dominar grande parte da Ásia para obter matérias primas e alimentos, escoar produtos industrializados, bem como a formar um espaço vital de defesa de seus interesses imperialistas na Ásia. O espaço vital era concebido a partir das premissas do geógrafo Ratzel, que foi um estudioso do Estado moderno, cuja existência se consolidava na defesa e expansão do seu território. Para justificar o imperialismo elaborou o conceito de espaço vital, segundo o qual haveria condições espaciais e naturais para a manutenção e consolidação de alguns Estados modernos (MOREIRA, 1990) O grande atraso no desenvolvimento econômico capitalista japonês aos moldes de alguns países no ocidente serviu de mote para novos rumos na política do país.

Tal conceito foi fundamental diante do contexto histórico japonês, que havia acabado de passar pelo seu processo de modernização e necessitava de uma base para justificar e se afirmar enquanto Estado, num processo de crescimento, expansão e dominação capitalista.

Com a grande depressão de 1929 no Japão fortaleceram-se setores nacionalistas conservadores (exército e capitalistas monopolistas), ou seja, com interesses imperialistas. Nesse contexto, japoneses invadem a China em 1937 ocupando a cidade de Nanquim, capital 
do país e sede do governo. Essa invasão chinesa pelo Japão deixou entrever um modelo de fascismo nipônico. O fascismo é aqui entendido como um sistema autoritário de dominação que surge na fase imperialista do capitalismo e não foi exclusivo de países como a Itália e Alemanha. Segundo Leandro Konder (2009) o sistema procurou se fortalecer durante a implantação do capitalismo monopolista de Estado favorecendo a concentração de capital. Quanto a demais característica Konder expõe:

[...] é um movimento político de conteúdo social conservador, que se disfarça sob uma máscara 'modernizadora' guiada pela ideologia de um pragmatismo radical, servindo-se de mitos irracionalistas e conciliando-os com procedimentos racionalistas-formais de tipo manipulatório. (KONDER, 2009, p. 53).

Neste modelo destacam-se no Japão, a superioridade racial e a pureza da raça, a valorização das virtudes militares, a forte hierarquia, o culto ao imperador, dissolução dos partidos e fim dos sindicatos. Porém, o fascismo japonês também tendia a revelar aspectos de continuidade com a cultura milenar do país na qual não havia uma política de terror e uma doutrina de massa tal qual no fascismo alemão. Segundo Moore, o fascismo precisava ser analisado quando associado ao desenvolvimento capitalista:

[...] o grande negócio necessitava do fascismo, do patriotismo, do culto ao imperador e do militarismo, tal como o exército e os patriotas necessitavam de que a grande indústria levasse a cabo o seu programa político. (MOORE, 1967 apud RODRIGUES, 2000, p. 182).

O grande negócio visava a ação militar imperialista do Japão que teve continuidade com o ataque a base de Pearl Harbor no Havaí e em 1942 no Pacífico. Enquanto inimiga da China e esta ainda aliada dos EUA, o Japão passa por boicotes econômicos e embargos comerciais. Até 1940, o país consegue resistir aos interesses dos Aliados através de pacto com a Alemanha e Itália.

Os interesses imperialistas em choque empurravam o Japão para uma guerra com os EUA principalmente após o ataque a base militar de Pearl Harbor. Sabe-se que não era uma investida surpresa para os norte-americanos e sim serviu para conformar a opinião pública dos EUA para a participação do país na guerra (PADROS; RIBEIRO; GERTZ, 2000). Após vitórias japonesas em 1942, a situação mudou a partir do segundo semestre desse ano e o país se voltou para a defesa interna, mesmo que atacado por bombas americanas. O Japão não conseguiu se reestruturar para a guerra com os EUA, pois suas fontes de matérias-primas 
estavam fora da ilha. Isso dificultava as comunicações e intercâmbios japoneses devido o controle marítimo dos EUA naquela região.

A partir de 1944 somam-se os fracassos militares (RODRIGUES, 2000) com várias vitórias americanas em Iwo e Okinawa (territórios do Japão). A resistência se compunha também pelos kamikazes conhecidos como pilotos suicidas e isto servira como argumento para os EUA lançar as duas bombas sobre o país. Tratou-se de um conflito em que a tecnologia e a capacidade de reconversão industrial revelaram a capacidade e superioridade dos norte-americanos no Pacífico.

Para representar as tramas dos pilotos kamikazes, lançou-se o romance "Zero Eterno" (Eien no Zero no original) que foi publicado em 2006. Naoki Hyakuta tornou-se um fenômeno editorial no Japão ${ }^{5}$. O romance virou um mangá através da arte de Souichi Sumoto. No Brasil foi publicado pela editora JBC em cinco volumes. A adaptação para o cinema em 2013, levou a liderança das bilheterias do Japão com mais de 8 bilhões em arrecadação. Em 2015, a trajetória de Kentaro Saeki em busca da história de seu avô kamikaze foi adaptada para a TV, em uma minissérie de três capítulos. (HYAKUTA; SUMOTO, 2015).

A narrativa do mangá se funde com os problemas históricos vivenciados durante a Segunda Guerra Mundial pelo Japão, mormente no que se refere à concepção ideológica do piloto kamikaze, avô do protagonista da história, Kentaro Saeki, no qual se recusava a morrer pelo seu país e, desta forma, era visto como alguém que não detinha o amor à pátria e, por consequência, não fazia jus ao cargo que ocupava.

Observa-se que o comprometimento que os pilotos kamikazes detinham com o próprio país ia de encontro à cultura que se disseminava em suas mentes e corações. A propósito, a cultura era arraigada na população japonesa de tal maneira que se permeava em bases ideológicas bastante sedimentadas:

Nesse sentido, a Cultura é ela própria uma espécie de símbolo romântico, como o infinito que assume uma encarnação local. Ela é o ponto imóvel do mundo em rotação no qual se intersectam tempo e eternidade, os sentidos e o espírito, o movimento e a imobilidade. (EAGLETON, 2011, p. 82).

\footnotetext{
${ }^{5} \mathrm{O}$ mangá lançado pela editora JBC (Japan Brazil Communication) no Brasil obedeceu a mesma quantidade de volumes e periodicidade lançados no Japão, ou seja, em torno de cinco volumes e mensal. (HYAKUTA; SUMOTO, 2015).
} 
É no próprio conceito de cultura que se dissociam outras peculiaridades dos indivíduos japoneses, é nesse repertório em que se conectam a unicidade e a multiplicidade, a sua ligação entre o individual e o mundo em que vivem, demonstrando ser o espírito da humanidade com propósitos singulares:

O que a própria cultura estima não é o particular, mas algo muito diferente, o indivíduo. Com efeito, ela vê uma relação direta entre o individual e o universal. É na unicidade de alguma coisa que o espírito do mundo pode ser mais intimamente sentido; mas revelar a essência de alguma coisa significa despi-la de seus particulares acidentais. $O$ que constitui minha própria autoidentidade é a autoidentidade do espírito humano. O que me faz aquilo que sou é minha essência, que é a espécie à qual pertenço. A Cultura é em si mesma o espírito da humanidade individualizando-se em obras específicas; e o seu discurso liga o individual e o universal, o âmago do eu e a verdade da humanidade, sem a mediação do historicamente particular. (EAGLETON, 2011, p. 84).

A narrativa, portanto, se envereda pela cultura por meio de um olhar histórico onde são demonstradas por sujeitos que vivenciaram a ambientação da segunda guerra. É nesta seara que aduz a utilização deste mangá como fonte histórica a entender uma cultura voltada para a obediência às regras impostas e aos valores tradicionais preestabelecidos pela sociedade japonesa. Assim, a captação desses valores pelos alunos, se tornam elementos a serem trabalhados num contexto escolar, permitindo que o ensino de história se torne uma "peça fundamental" para a transmissão de valores com enfoque cultural diverso, juntamente com o fato de que a linguagem utilizada pelo mangá, tida como dinâmica e interativa, permita que o ensino de história flua a temas considerados prolixos e enfadonhos, como os conceitos de cidadania e identidade nacional.

No que se refere a trama, esta narra a história de Kentaro Saeki, um jovem de 26 anos que sente sua vida estagnada. Ele fora reprovado no Exame Nacional de Advocacia, e com isso o rapaz sentiu a falta de uma nova motivação de trabalho e acadêmica. A mudança ocorre quando sua irmã Keiko o contrata para pesquisar quem foi Kyuzo Miyabe, avô de ambos que batalhou nos céus da Guerra do Pacífico, pilotando um caça Mitsubishi A6M Zero, e morreu em missão pelo Tokkotai, a esquadra de pilotos suicidas durante a Segunda Guerra Mundial. 


\section{Figura 01 - Capítulo I do Mangá “Zero Eterno": Meu Verdadeiro Avô}

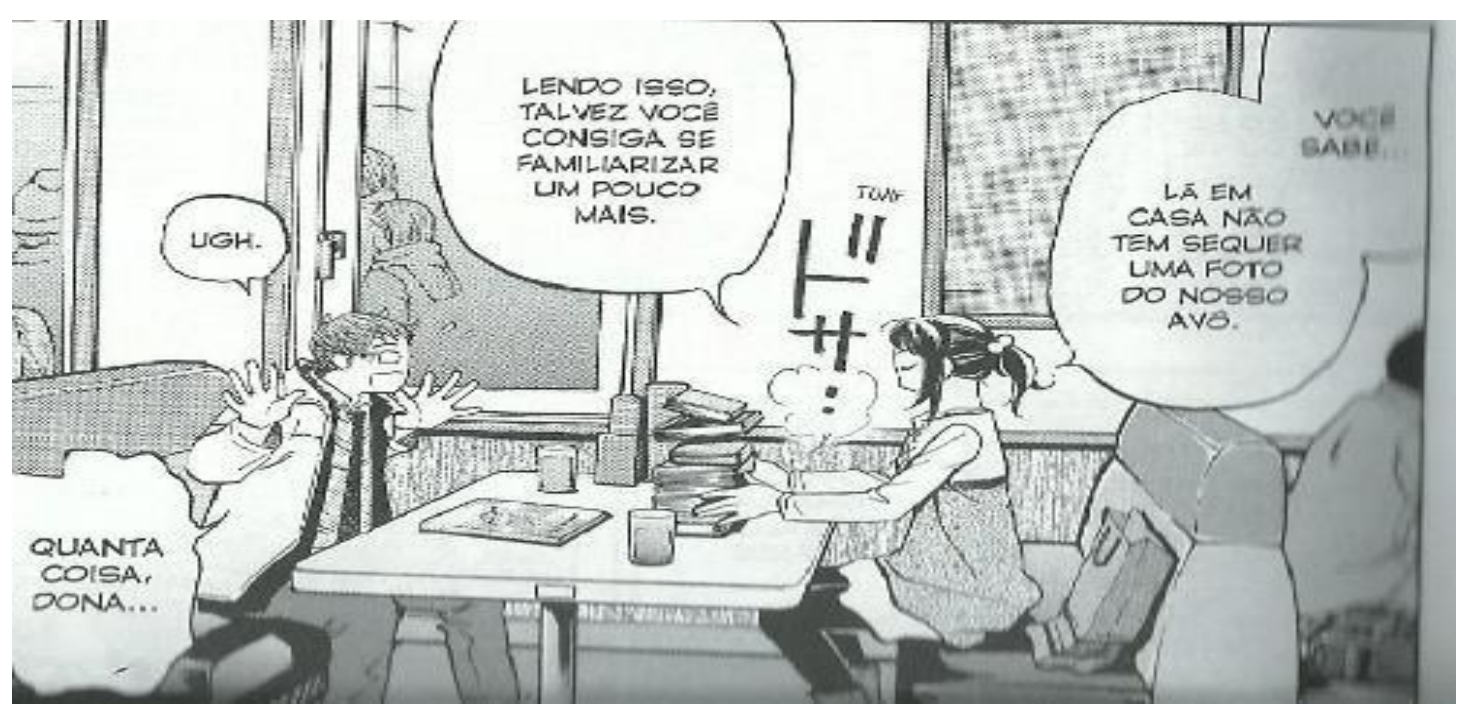

Fonte: HYAKUTA; SUMOTO, 2015, V. I, p. 27.

A partir da imagem acima, Kentaro inicia suas pesquisas e entrevista sete excombatentes da grande guerra e escreve sobre o modo de pensar daqueles que sobreviveram durante a guerra e confronta-os com o presente que não parece entender a atuação dos kamikazes. Com esse romance histórico podemos conhecer aspectos da Segunda Guerra Mundial sob o olhar japonês, descobrindo detalhes e temas diferentes do conhecido pela maioria das pessoas, principalmente no Ocidente. (HYAKUTA; SUMOTO, 2015).

O título Eien no Zero, ou Zero Eterno, em tradução literal, se refere ao tema central da obra, ou seja, os pilotos kamikazes e especificamente aos caças que usavam e, por extensão, os próprios pilotos, também eram apelidados de Zero por causa da missão e pela obrigação de muitos morrerem pelo país.

Zero Eterno apresenta durante as pesquisas e no diálogo dos irmãos aspectos da história da participação do Japão nas batalhas e cenas de aviões na Segunda Guerra Mundial. É um mangá que desperta a curiosidade, sobretudo pelos sobreviventes que se intrigam com questões como a honra e a luta pela vida em tempos difíceis. A busca por pessoas civis e militares vivas e que poderiam relatar o período e quem foi o avô desconhecido torna a história instigante. Apenas enquanto adultos souberam da existência do avô biológico. $\mathrm{Na}$ trama descobrem que ele nasceu em 1919 em Tóquio. Alistou-se em 1934 e morreu em 1945 
nas águas do arquipélago Nansei. Dos quinze aos 26 anos dedicou-se as forças armadas. (HYAKUTA; SUMOTO, 2015, V. I, p. 10-11).

Ironicamente a primeira entrevista foi com ex-tenente da marinha que esteve em combates com o seu avô. Este criticava o modo de lutar de Myabe porque optou em sobreviver nos combates do que morrer nas batalhas. $\mathrm{O}$ avô que lutava para viver, morreu e o ex-tenente sobreviveu embora preferisse se sacrificar pelo país.

Figura 02 - Capítulo IV do Mangá “Zero Eterno": A "Esperança” vem do Céu

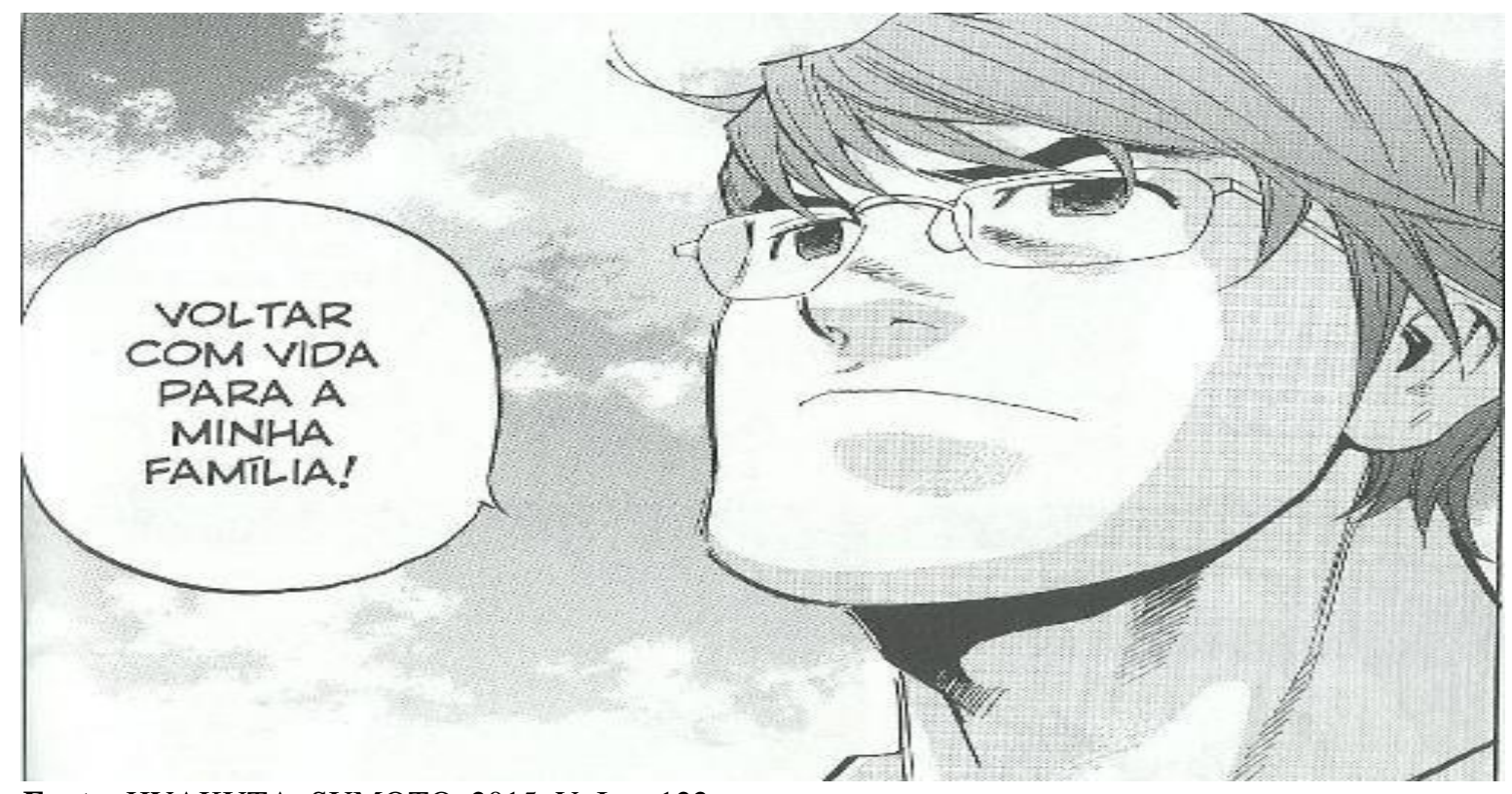

Fonte: HYAKUTA; SUMOTO, 2015, V. I, p. 122.

Segundo esse entrevistado ter medo de morrer era incabível naqueles tempos. A morte fazia parte daquele cotidiano (HYAKUTA; SUMOTO, 2015, V. I, p. 83). No texto, aponta-se as razões da luta do avô pela vida em tempos de guerra: "Tentar entender os sentimentos daqueles que combateram não é algo fácil. Mesmo considerando que os valores de Kyuzo pareciam estranhos para a época em que ele vivia" (HYAKUTA; SUMOTO, 2015, V.I, p. 100-1). Na imagem que segue olhares do ex-tenente da marinha Hasegawa: 


\section{Figura 03 - Capítulo II do Mangá "Zero Eterno": O "Covarde” que prezava pela vida}

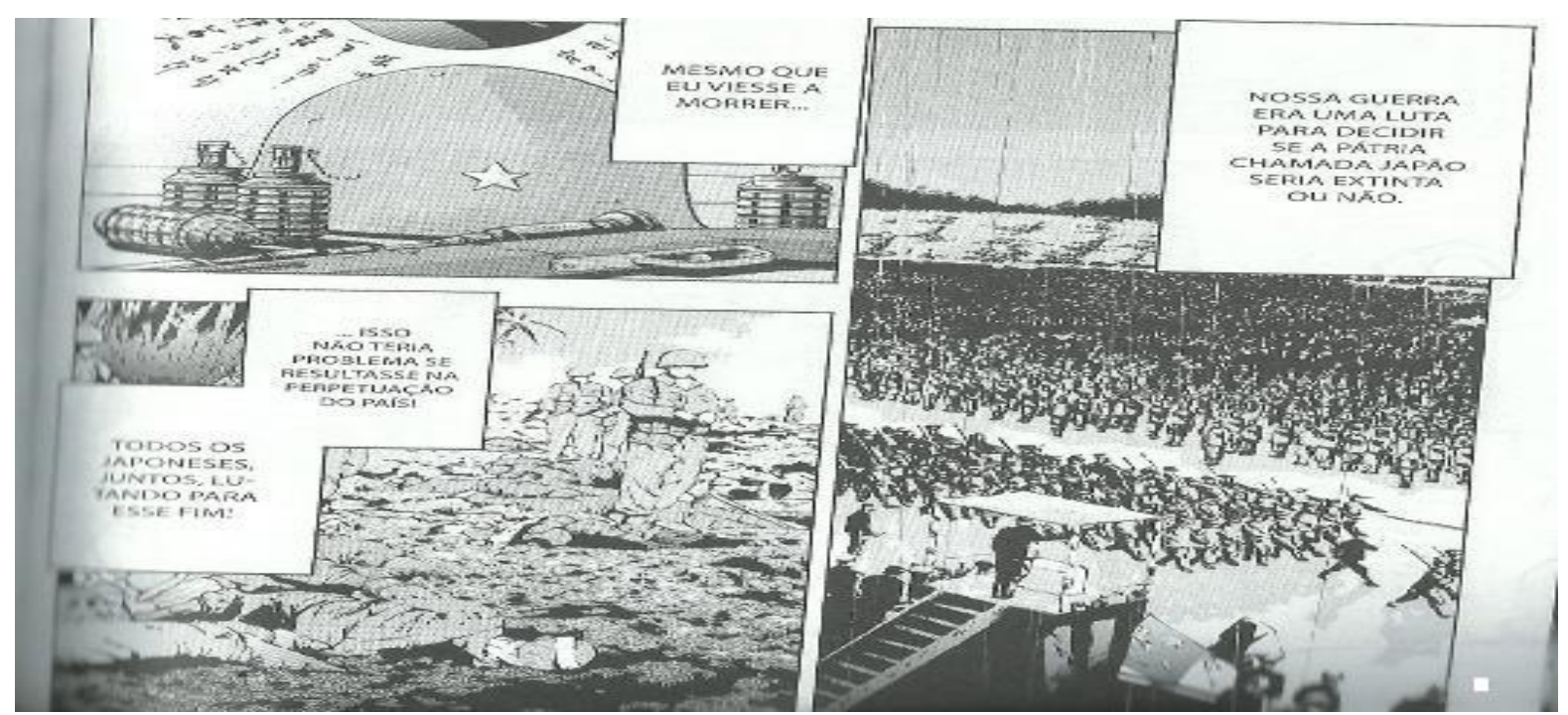

Fonte: HYAKUTA; SUMOTO, 2015, V. I, p. 83.

O sentimento de pertencimento a nação tornou possível que tantos homens fossem à guerra. Segundo Benedict Anderson nação também é um artefato cultural de tipo peculiar com significados múltiplos em processo advindo do cruzamento de forças históricas que sustentaram afetos profundos (ANDERSON, 1989, p. 12). Nesse sentido, esse autor ainda ressalta que:

Assim, num sentido positivo, o que tornou imagináveis as novas comunidades foi uma interação entre um sistema de produção e de relações produtivas (capitalismo), um a tecnologia de comunicações (a imprensa) e a fatalidade da diversidade linguística do homem. (ANDERSON, 1989, p. 48-52).

No Japão o sentimento de nacionalidade no século XX é construído nesse contexto elencado por Benedict Anderson. 


\section{Figura 04 - Capítulo XXX do Mangá “Zero Eterno”: Entrelinhas}

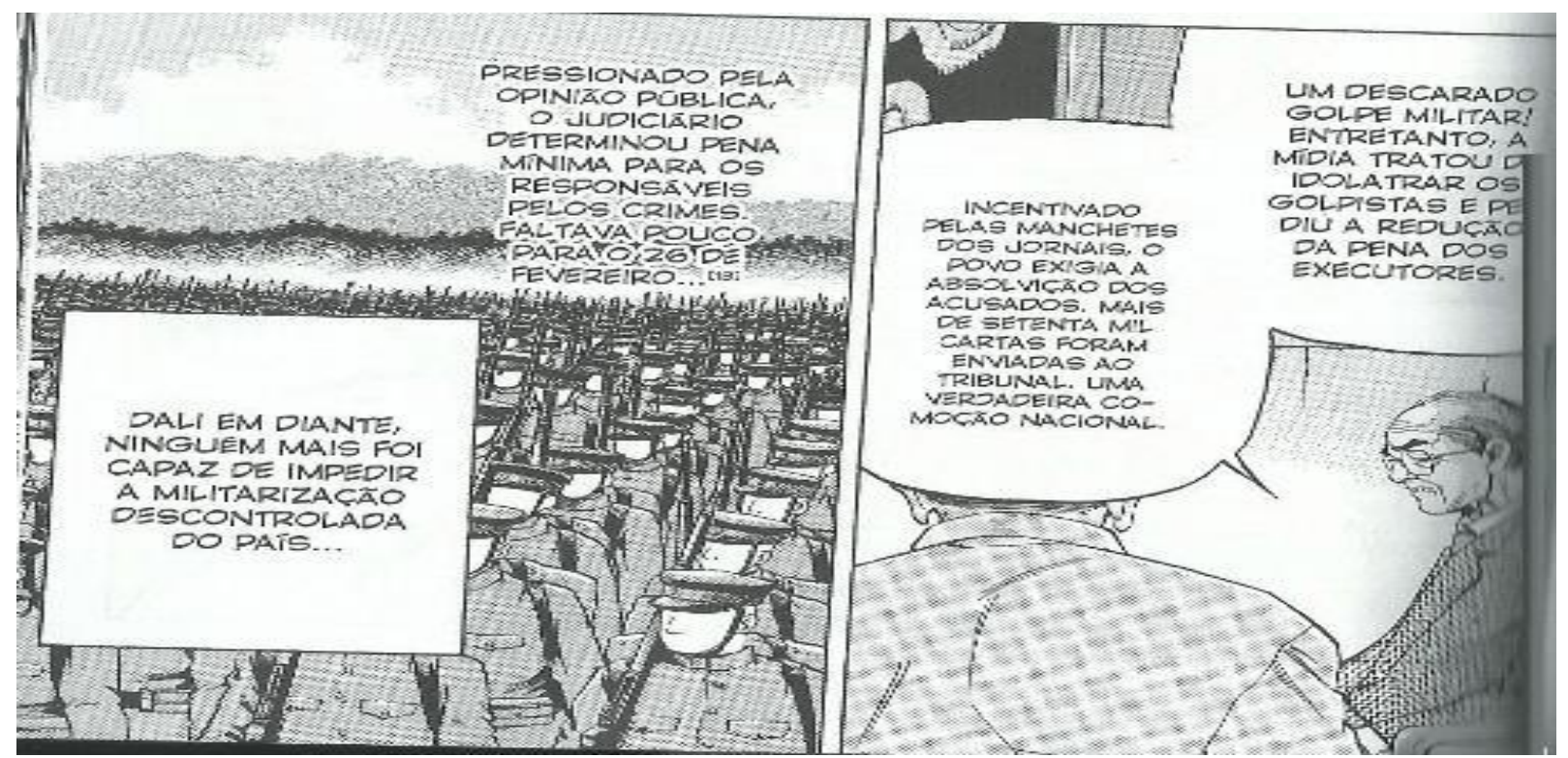

Fonte: HYAKUTA; SUMOTO, 2015, V. 4, p. 167.

Neste sentido, a mídia japonesa da época, juntamente com o Estado foram responsáveis por inflar o sentimento de patriotismo no povo japonês e essa característica pode ser notada com o grande poderio bélico que foi alcançado antes da Segunda Guerra Mundial, momento este em que o Japão incentivou uma militarização maciça pela população e que, somente após o fim da guerra, foi desestimulada pela imprensa e pelo Estado, já que o país, após esse período, não se encontrava em condições de viabilizar um nacionalismo pautado em armamentos militares. O Japão se encontrava num colapso financeiro e não mais importava ao Estado sua militarização, mas sim a sua reestruturação política e econômica.

O país era governado pelo imperador Hiroito e no seu reinado de 1926-1989, o Japão tornou-se uma das maiores potências econômicas e país permanente do conselho da Liga das Nações. Enquanto chefe de Estado sob a limitação da Constituição do Império do Japão, promoveu uma intensa militarização do país e participou diretamente da Segunda Guerra Mundial como país do Eixo.

Nesse contexto, ex-combatente advogava que os jornais foram os principais responsáveis pela ascensão do militarismo no Japão (HYAKUTA; SUMOTO, 2015, V.4, p. 168) A opinião popular fora manipulada pelos meios de comunicação.

A literatura quadrinizada também foi utilizada com esse propósito ideológico como, por exemplo, os “Quadrinhos de Mao" que se constituíram, na década de 1960, uma estratégia 
para difundir ideais do líder Mao Tsé-Tung. O ocidente conheceu essa produção através do livro de Umberto Eco, "I fumetti di Mao (traduzido para o espanhol como Los Comics de Mao), (CERRI; BONIFÁCIO, 2006, p. 3444).

O sucesso dessas histórias em quadrinhos junto ao público infanto juvenil, abriu a possibilidade do uso dessas histórias para a difusão de princípios e ideologias, “[...] com o objetivo de formar (ou incutir) valores, transmitir conhecimentos, resgatar conceitos de cidadania e identidade nacional, através do destaque à construções históricas e consideradas como relevantes à nação e ao sentimento nacional" (CERRI; BONIFÁCIO, 3443). Nesse sentido, representar olhares sobre a ação dos kamikazes reabre a possibilidade de debater a atuação destes na medida que são comparados aos terroristas chamados de homens-bomba do tempo presente.

\section{KAMIKAZES E AÇÕES TERRORISTAS: APONTAMENTOS}

Um dos focos do conjunto da obra foi rediscutir a atuação dos kamikazes na tentativa de debater as comparações com os terroristas do presente bem como mostrar que suas ações não foram espontâneas e sim obrigatórias e induzidas pelo alto comando militar japonês.

Nesta discussão cabe inferir sobre algumas definições conceituais. Segundo o dicionário Aurélio, terrorismo tem os seguintes significados, "1. Modo de coagir, ameaçar ou influenciar outras pessoas ou de impor-lhes a vontade pelo uso sistemático da força. 2. forma de ação política que combate o poder estabelecido mediante o emprego da violência”. (AURÉLIO, p. 632).

Segundo o dicionário de política:

[...] é a estratégia escolhida por um grupo ideologicamente homogêneo, que
desenvolve sua luta clandestinamente entre o povo para convencê-lo a recorrer a: 2)
ações demonstrativas que têm, em primeiro lugar, o papel de 'vingar' as vítimas do
terror exercido pela autoridade e, em segundo lugar, de 'aterrorizar' esta última,
mostrando como a capacidade de atingir o centro do poder é o resultado de uma
organização sólida e 3) de uma mais ampla possibilidade de ação: através de um
número cada vez maior de atentados (veja -se a sua sucessão nos anos de 1878 a
1881 na Rússia) que simboliza o crescimento qualitativo e também quantitativo do
movimento revolucionário. (BOBBIO et al, 2000, p. 125).

Leonardo Boff define: “[...] é toda violência espetacular, praticada com o propósito de ocupar as mentes com medo e pavor $(2014$, p. 1). Para este autor, deve-se contemplar que o 
terrorismo não é um fenômeno da guerra, mas da política. "O terrorismo irrompe no seio de grupos insatisfeitos com os rumos da política do país ou da economia e que já não acreditam nas instituições, nem no diálogo e muito menos em mudanças sociais significativas". (BOFF, 2014, p. 01).

Mas, segundo Maia, o professor Francisco Carlos Teixeira da Silva lembra que o terrorismo é uma prática antiga advinda com a própria humanidade:

\begin{abstract}
Os antigos assírios já cortavam as árvores e envenenavam os poços de água dos inimigos - numa região desértica isso era muito grave. Mas no século XX, isso assumiu proporções de política de Estado e atingiu de forma espetacular, dada a própria globalização, proporções até então nunca vistas na História. Essa é a exclusividade do século XX: o caráter espetacular do terrorismo de massas. (MAIA, 2007, p. 01).
\end{abstract}

De modo geral, conceitos e definições de terrorismo o entendem como tática para se alcançar determinado objetivo (intimidar, coagir, combater) com o uso da violência, com ataques à população civil e a instituições públicas e bens privados. Os motivos podem ser políticos, sociais ou religiosos, imbuídos do desejo de vingança, ódio e ou sentimento separatista.

No contexto desta pesquisa há de observar a ação dos kamikazes naquele contexto militar da grande guerra. Até a batalha de Midway ${ }^{6}$, o Japão havia triunfado sobre os países aliados. Conforme depoimento: “Até então a marinha japonesa só havia triunfado. Nenhuma batalha perdida! Vitórias arrasadoras!! Inflados por uma enorme confiança enfrentamos a grande potência americana. A arrogância havia nos cegado" (HYAKUTA; SUMOTO, 2015, V. 2, p. 128). Devido a bombardeios de mergulho em ataques surpresas ocorrem mudanças no rumo da guerra no pacifico. Cinco porta-aviões japoneses foram abatidos durante aquela batalha e isso enfraqueceu permanentemente a capacidade de combate no mar e no ar, lhes retirando a iniciativa militar (HYAKUTA; SUMOTO, 2015, V. 2, p. 172).

As vésperas do fim da guerra a maioria dos pilotos novatos foram enviados para a missão tokko ${ }^{7}$, inclusive o avô Myabe, embora não fosse novato. Segundo depoente: "Eles eram os mais descartáveis.

\footnotetext{
${ }^{6}$ Foi uma das maiores batalhas aeronavais ocorrida em junho de 1942 no Oceano Pacífico entre as forças dos Estados Unidos e japonesas. Com a vitória norte-americana a guerra toma novos rumos no pacífico.

${ }^{7}$ O nome oficial dos kamikazes era Tokubetsu Kōgekitai (Unidade de Ataque Especial), também conhecidos pela abreviação Tokkōtai ou Tokkō.
} 
Os pilotos tokko tinham que terminar o treinamento em menos de um ano. Eles não treinavam para lutar, treinavam para morrer" (HYAKUTA; SUMOTO, 2015, V. 2, p.186). As vésperas do fim da guerra, o oficial Myabe, que tanto queria voltar para casa foi enviado para uma missão suicida. (HYAKUTA; SUMOTO, vol. 2 p. 187)

No primeiro volume a irmã reflete sobre a imagem construída sobre os kamikazes em relação ao terrorismo:

Dizem que o Tokkotai era um grupo terrorista. Tipo aqueles que derrubaram as torres gêmeas em Nova York, sabe? De acordo com um jornalista que conheci nesse projeto os pilotos do tokkotai foram os terroristas daquela época. Ele me emprestou um livro de testamentos de ex-membros da unidade. O texto esta repleto de expressões como 'dever com a pátria' e 'lealdade ao império'. Os pilotos do tokkotai não tinham medo de morrer pelo contrario morrer pela nação dar sua vida pela pátria. Dependendo o ponto de vista os membros do tokkotai também eram terroristas, mártires, extremistas ultranacionalistas. (HYAKUTA; SUMOTO, 2015, V. 1, p. 30- 35).

Partindo dessas indagações é que os dois jovens partem para a pesquisa nas associações de veteranos da guerra com o objeto de entrevistar sobreviventes e excombatentes.

Alguns diários desses pilotos mostravam que tinham orgulho de morrer pelo país. Porém naquele período, era divulgado apenas o que pudesse servir como propaganda ideológica, nos quais se inseriam relatos e testamentos que exaltassem a nação japonesa, a devoção pelo imperador e poemas de morte mencionando a sakura (flor da cerejeira), enquanto um símbolo nacional. $\mathrm{O}$ quarto volume atenta para o fato de que a censura não permitiu que aflorassem criticas ou que expressassem seus sentimentos. Nenhuma critica à guerra ou ao comando militar era permitida. Assim como qualquer declaração que pudesse ser interpretada como imprópria pelos censores. (HYAKUTA; SUMOTO, 2015, p. 157-158). 


\section{Figura 05 - Capítulo XXX do Mangá "Zero Eterno": Entrelinhas}

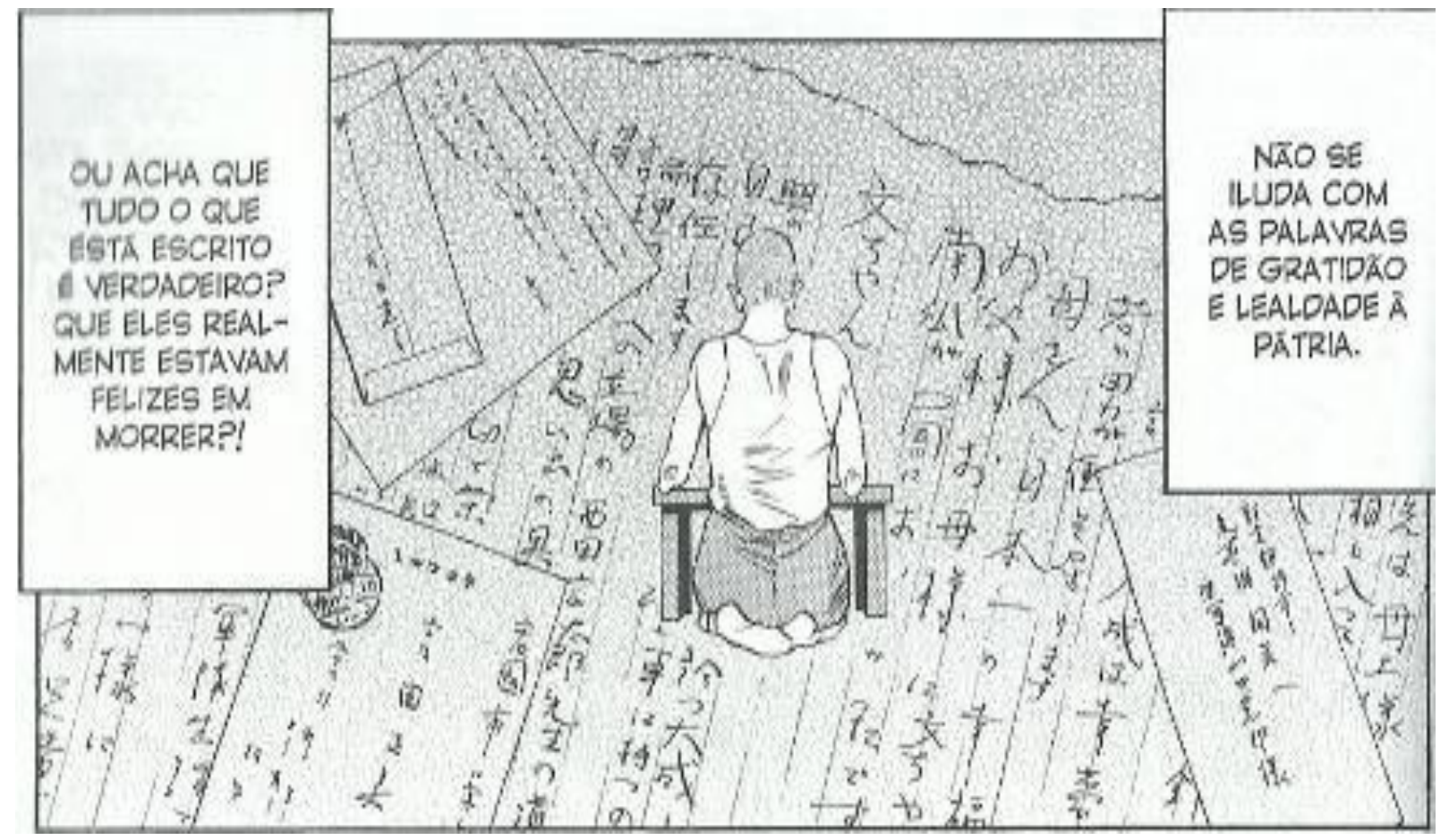

Fonte: HYAKUTA; SUMOTO, 2015, V. 4, p. 159.

Segundo Fabio Marton (2013) evita-se comparações com os homens-bomba porque os kamikazes eram recrutados como parte dos soldados japoneses e recebiam ordens para morrer em ataques às bases militares inimigas e não tinham como alvo civis.

Nos Estados Unidos, as primeiras informações sobre os kamikazes foram divulgadas em abril de 1945 e os meios de comunicação os representaram como fanáticos. Estes não eram nem fanáticos, nem voluntários e sim “(...) os jovens pilotos suicidas japoneses foram vítimas da hierarquia militar e de um projeto tão ousado quanto estúpido para tentar reverter uma invasão que não chegou a acontecer" (MARTON, 2013, p. 28). Na imagem abaixo representa-se o início do recrutamento para aquele ataque suicida, na qual nenhum piloto se voluntariou. 


\section{Figura 06 - Capítulo XXX do Mangá “Zero Eterno": A origem do tokkotai}

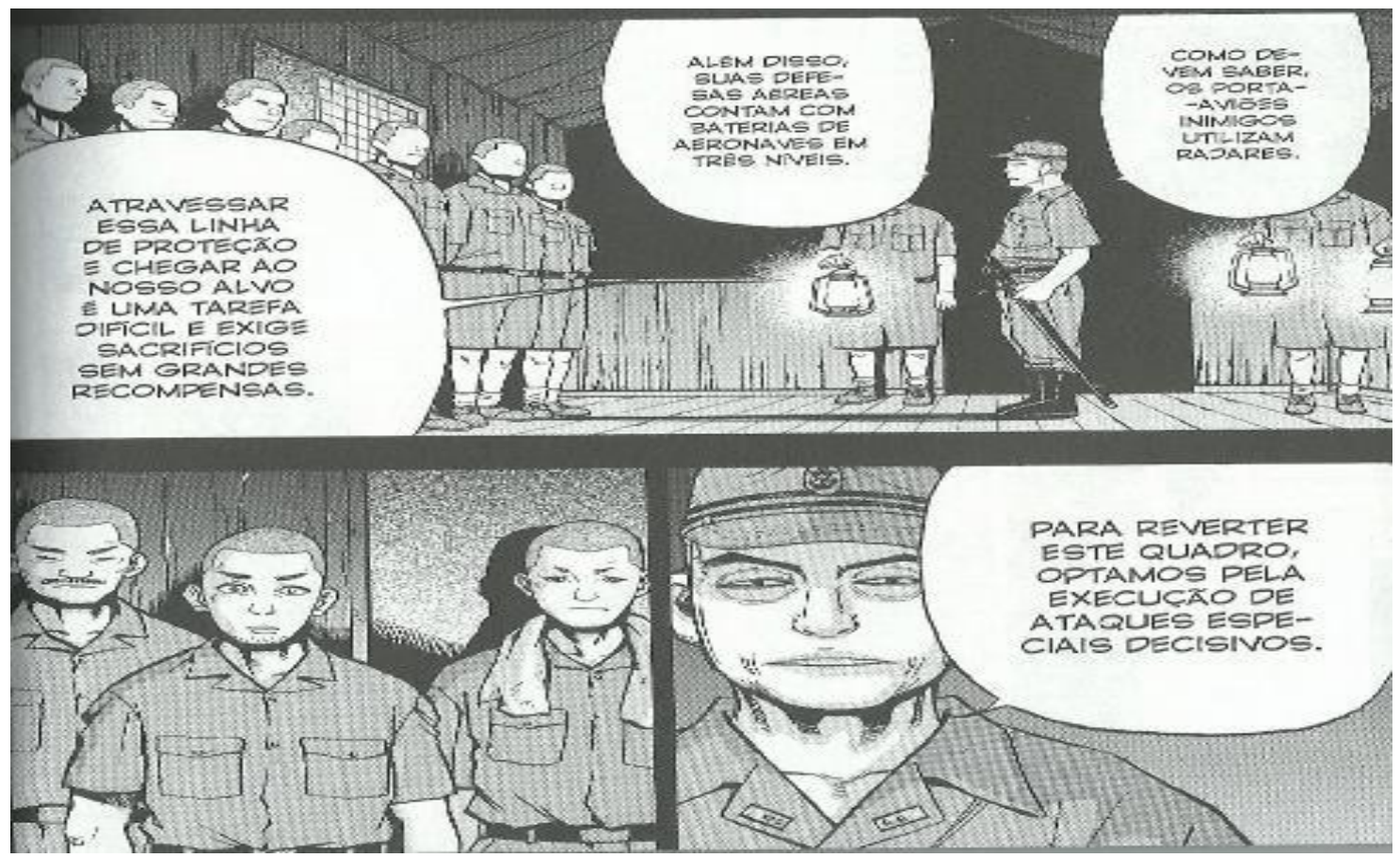

Fonte: HYAKUTA; SUMOTO, 2015, v. 4, p. 140.

Ao trazer à tona o olhar dos sobreviventes há de se ressaltar que os estudos relativos às subjetividades trazem em si uma perspectiva histórica pautada por valores éticos, os quais são recentes e pouco visibilizados. Ao focar nos estudos deste tipo de literatura em quadrinhos pululam experiências históricas que podem fortalecer a construção de outros olhares históricos sobre a grande guerra. Igualmente, muitos dos estudos críticos tendem ou tenderam a denunciar as formas da opressão existentes no passado e no presente, deixando, porém, de enfatizar a importância das inventividades, dos pormenores, dos sopros de existência. Foucault nesse sentido considera:

Não posso me impedir de pensar em uma crítica que não procurasse julgar, mas que procurasse fazer existir uma obra, um livro, uma frase, uma ideia. Ela acenderia fogos, olharia a grama crescer, escutaria o vento e tentaria apreender o voo da espuma para semeá-la. Ela multiplicaria não os julgamentos, mas os sinais da existência, ela os provocaria, os tiraria de seu sono. Às vezes, ela os inventaria? Tanto melhor, tanto melhor. A crítica por sentença me faz dormir. Eu adoraria uma crítica por lampejos imaginativos. Ela não seria soberana, mas vestida de vermelho. Ela traria a fulguração das tempestades possíveis. (FOUCAULT, 2004, p. 925). 
Nesse sentido, o texto literário dá vida, faz existir e traz configurações que contornam e conformam o objeto sem esquadrinhamentos conceituais. Também abre portas de entrada para novos acontecimentos interpelados pelas subjetividades. O discurso narrativo do mangá "Zero Eterno" analisado neste artigo, nos mune de um olhar atento ao breve, ao minúsculo e aquilo que é sensível as singularidades da experiência e das diferenças humanas.

Assim, para se desenvolver essas idiossincrasias se faz necessário trabalhar às histórias em quadrinhos por meio de uma metodologia capaz de reunir a cultura histórica do Japão e as idéias que os alunos irão desenvolver com os conteúdos abordados. Na medida em que a narrativa histórica deságua numa aprendizagem de consciência histórica dos alunos, problematizando-os a respeito da existência e interconexão de uma cultura diversa, o ensino de história alcançará seu objetivo metodológico:

Para que haja certo grau de plausibilidade no uso de histórias em quadrinhos com temas históricos torna-se necessário, além do conhecimento de sua linguagem específica enquanto documento produtor de evidências históricas, o confronto entre as narrativas históricas gráficas que já seguem uma estrutura fundamentada na epistemologia da História. Possivelmente este confronto narrativo permitirá a potencialização, nos estudantes, da capacidade de narrar historicamente por meio das histórias em quadrinhos com temas históricos. (FRONZA, 2012, p. 08-9).

Ao problematizar as subjetividades para além dos estudos psicológicos e ou psicanalíticos questionamos as práticas por meio das quais os indivíduos se constituem em relação aos códigos morais, crenças, valores, disposições éticas, emoções e diferentes sentimentos. Nesse sentido, é novamente Foucault que observa que a subjetividade é fruto de vários elementos sociais e assumida e vivida pelos indivíduos em suas existências particulares. Para Foucault, a palavra pode ser entendida como a maneira pela qual o sujeito faz a experiência de si mesmo num jogo de verdade, no qual ele se relaciona consigo mesmo. (FOUCAULT, 2004).

Nessa questão das subjetividades a obra também resgata conceitos de cidadania e identidade nacional, pois através da pesquisa do jovem Kentaro reporta-se as construções históricas da guerra no pacífico e das relações de poder entre o comando militar, pois tais questões também são relevantes à nação e ao sentimento nacional japonês. Daí seu sucesso editorial e fílmico. A partir destas subjetividades foi possível perceber que os kamikazes em sua maioria não optaram pela batalha suicida e sim, foram encurralados para a morte. 


\title{
4 ENSINO DE HISTÓRIA E A LINGUAGEM DOS MANGÁS
}

Estas histórias em quadrinhos inserem-se nas novas tendências do ensino e pesquisa, ou seja, em outras possibilidades de se narrar e resgatar uma história tão distante e também esquecida. Os fatos históricos passam a ser vividos pelos kamikazes e adquirem outros contornos, olhares e causas pelas quais lutar.

Conforme apontam Cerri e Bonifácio:

As palavras e tramas passam a capturar a atenção e a identificação do leitor para com o enredo, com o roteiro. Entender a linguagem dos quadrinhos, compará-los com outras linguagens, lê-los também de forma prazerosa, [...] inserir um pouco de bom humor, de leitura-prazer, de ficção, de imaginação, são horizontes a serem ainda muito explorados no espaço escolar [...]. De todo modo, uma sociedade caracterizada pela grande presença das mídias e linguagens, possibilita e exige de todo educador e de todo professor de História - uma tomada de postura: de ir além dos limites que já nos foram dados [...]. (CERRI; BONIFÁCIO, 2006, p. 3452).

Ainda de acordo com Cerri e Bonifácio, as histórias em quadrinhos caracterizam-se pelo uso de dois elementos comunicacionais, ou seja, a imagem e a escrita e possuem também as seguintes características:

\begin{abstract}
Ao limitar e congelar uma ação que, na realidade, é ininterrupta, o artista exercita a habilidade de narrar uma história com vários segmentos que, somados, fornecem uma estrutura narrativa completa. Desse modo, podemos inferir que os quadrinhos constituem uma linguagem, sobretudo interativa, pois precisa capturar e conduzir a atenção do leitor, fazendo com que o autor imprima e dite as regras da sequência narrativa. Além desses aspectos, há outros elementos referentes à linguagem dos quadrinhos, como o uso de balões e onomatopéias. Ao tomarmos a escrita como foco de análise, podemos afirmar que um recurso fundamental e marca registrada dos quadrinhos é o uso dos balões, que vêm a caracterizar a presença das emoções, pensamentos e diálogos nas histórias. (CERRI; BONIFÁCIO, 2006, p. 3446).
\end{abstract}

Em relação aos mangás sabe-se que são tributários dos teatros de sombras japonês, chamados Oricon Shohatsu. Acredita-se que estes teatros remontam ao período feudal do Japão, e por meio destes, artistas viajantes contavam histórias tradicionais do país. (MARTON, 2013).

Devido à popularidade destas histórias aos poucos foram registradas em rolos de papel e tecido contendo o texto e a ilustração. Sua expansão ocorreu no início do século XX, sendo impressas no formato de livros e em papel jornal, o que ampliou o número de leitores no Japão. Após a Segunda Guerra Mundial, os mangás receberam incentivo governamental 
através do Plano Marshall enquanto um recurso político ideológico. Na década de 1980 Marc Ferro já observava na academia a relação entre os meios de comunicação e manipulação de uma versão única dos fatos histórias e duas obras "A manipulação da história no ensino e nos meios de comunicação", de 1983, e “A história vigiada”, de 1989.

A influência dos quadrinhos vindos dos Estados Unidos, e também dos charges e outros cartuns influenciaram os artistas japoneses, chamados de mangakás, e assim o mangá adquiriu características contemporâneas como os olhos grandes, redondos, queixo pontiagudo e arredondado e sem regra fixa sobre o número de quadrinhos para cada página. Um dos artistas representativos desta arte foi Osamu Tezuka (1928-1989), responsável por criar histórias como Astro Boy e a Princesa e o Cavaleiro.

Além disso, é possível elencar outras características tais como emoções e ações exageradas, páginas com onomatopéias e imagens que ocupam toda a página. Apesar da tradução no ocidente os mangás são lidos de trás para frente assim como da direita para a esquerda.

Estes mangás também se caracterizam pelo modo de condução da trama parecido com muitos romances históricos, cujas histórias também ocorrem no tempo presente, com muitos diálogos, com trechos de flashback que possuem bem poucos diálogos.

Assim, é comum ao longo dos cinco volumes a arte sequencial com o uso de palavras que reproduzem sons, caracterizando mais umas das estruturas dos quadrinhos. Estas palavras podem ser o indicativo de quebra de objetos, som de batidas, espirros, risos, socos, etc. Os primeiros quadrinhos não possuíam essa arte.

\section{Figura 07 - Capítulo XXXII do Mangá “Zero Eterno”: Simulação de Combate}

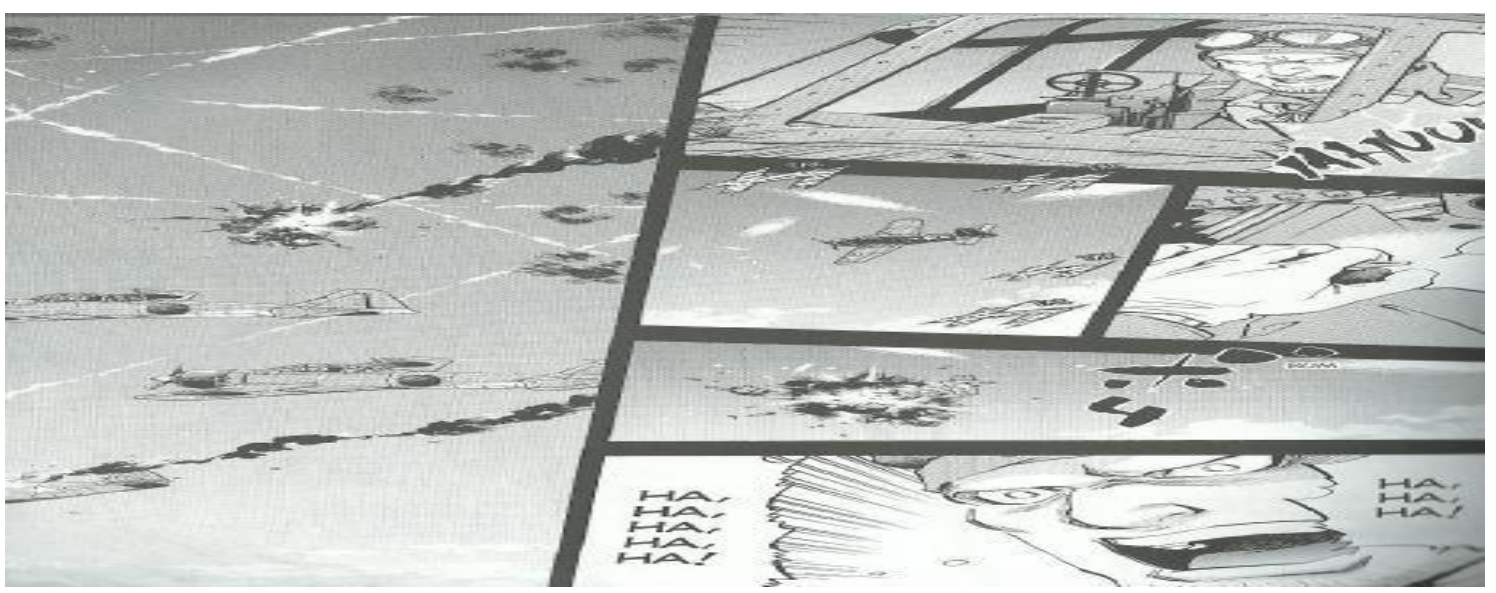

Fonte: HYAKUTA; SUMOTO, vol. 5, p. 13.

Interfaces da Educ., Paranaíba, v.7, n.21, p.204-227, 2016.

ISSN2177-7691 
A onomatopéia surge na década de 1920 conforme explica Cerri e Bonifácio:

\begin{abstract}
Na década de 1920, quando surgem os primeiros filmes sonoros em Hollywood, os quadrinhos precisam encontrar os ruídos, os barulhos, os sons que não se encontravam presentes nos balões, fosse o bater de uma porta, o som de um objeto quebrando ou os tiros de uma arma. Surgem, assim, as primeiras onomatopéias, conferindo aos quadrinhos o status de um importante veículo audiovisual, pois estabelece uma comunicação mais direta e completa. Salientamos, aqui, o quanto as histórias em quadrinhos têm caminhado, simultaneamente, com a linguagem cinematográfica, estimulando e sendo por ela estimuladas. (CERRI; BONIFÁCIO, 2006, p. 3446).
\end{abstract}

Zero Eterno configura-se numa nova possibilidade de ensino de História Contemporânea, sobretudo daquela história posta no esquecimento tanto pelos orientais como pelos ocidentais ou com versão única. Os inúmeros recursos visuais e a construção da linguagem dão novos contornos as experiências daqueles que viveram o contexto da guerra e delinea outras causas pelas quais se lutou. Conforme Cerri e Bonifácio observam:

Entender a linguagem dos quadrinhos, compará-los com outras linguagens, lê-los
também de forma prazerosa, produzi-los em sala de aula, individual ou
coletivamente, são apenas algumas das inúmeras possibilidades a serem utilizadas
pelo professor de História. Inserir um pouco de bom humor, de leitura-prazer, de
ficção, de imaginação, são horizontes a serem ainda muito explorados no espaço
escolar. A maioria das respostas ainda não está definida; o caminho a ser trilhado é
pleno de desafios. De todo modo, uma sociedade caracterizada pela grande presença
das mídias e linguagens, possibilita e exige de todo educador - e de todo professor
de História - uma tomada de postura: de ir além dos limites que já nos foram dados,
e descobrir novas fronteiras e perspectivas de ação pedagógica.
(CERRI;
BONIFÁCIO, 2006, p. 3452).

Assim, Zero Eterno é um mangá diferente das publicações anteriores e porque também aborda um período importante da história da humanidade e, que pelo tamanho que foi o conflito, possui tantas fontes e formas de se contar. Por isso, nos mangás as tramas passam a capturar a atenção e aos poucos a empatia dos leitores para com o enredo e o roteiro. Entender o que foi esse período de guerra no Pacífico coaduna com as palavras do primeiro volume "Não é um passado tão distante. Apesar disso... é uma era que não mais vive em nossas memórias (HYAKUTA; SUMOTO, 2015, p. 5), e por fim, parafraseando um sobrevivente, “Essas são palavras de quem só conhece tempos de paz" (HYAKUTA; SUMOTO, 2015, V. 1, p. 82) e aqueles que estiveram nas batalhas no período vivenciaram de outro modo o que este representou e os cinco volumes desta obra tiveram esse objetivo. 


\section{CONSIDERAÇÕES FINAIS}

Zero Eterno é um mangá singular em relação às publicações anteriores porque aborda um período ímpar na história da humanidade uma vez que, pelo tamanho que foi o conflito, possui novas fontes e formas de se contar a participação dos kamikazes na Segunda Guerra Mundial.

Os horrores desse período de guerra devem ser reconstruídos com novas narrativas históricas, pois é dessa forma que se inicia o primeiro volume "Não é um passado tão distante. Apesar disso... é uma era que não mais vive em nossas memórias (HYAKUTA; SUMOTO, 2015, p. 5), e só mesmo quem viveu no período sabe o que representou e a obra teve esse objetivo. Daí a relevância das subjetividades na história. Nesse sentido, o texto literário faz existir e traz configurações que contornam e conformam o objeto sem esquadrinhamentos conceituais. Também abre portas de entrada para novos acontecimentos interpelados pelas subjetividades e neste mangá os olhares daqueles que querem revelar outras facetas daquela história.

O discurso narrativo do mangá "Zero Eterno" analisado neste artigo, nos mune de um olhar atento ao breve, ao minúsculo e aquilo que é sensível as singularidades da experiência e das diferenças humanas. Por meio destes olhares é que podemos rever algumas abordagens dadas sobre os kamikazes bem como a tendência a compará-los com terroristas do presente. Os jovens pilotos suicidas japoneses em sua maioria não eram fanáticos, ou voluntários e sim vítimas do alto comando militar numa tentativa de reverter a derrota japonesa em curso.

Em relação ao ensino de história urge interpelar novas metodologias que o tornem mais prazeroso. Conforme nos alude Cerri e Bonifácio (2006) a inserção de um pouco de bom humor, de leitura prazerosa, de ficção, de imaginação, são possibilidades pelas quais pouco trilhamos no ensino fundamental e médio. Se ainda há muitas indagações e também desafios em uma sociedade marcadamente caracterizada pelo uso constante dos meios de comunicação, principalmente, pelas crianças e adolescentes então essas linguagens do cotidiano possibilitam e talvez nos instiguem a reverter um ensino enfadonho e ir além dos limites dados nas escolas e, assim, quiçá se aventurar na literatura quadrinizada.

\section{REFERÊNCIAS BIBLIOGRÁFICAS}

ANDERSON, Benedict. Nação e consciência nacional. São Paulo: Ática, 1989. 
BOBBIO, Norberto et al. Dicionário de Política. Brasília/São Paulo, UnB/Imprensa Oficial, 2000, p.1252-1254.

BOFF, Leonardo. Por uma definição de terrorismo. Disponível em:

$<$ https://leonardoboff.wordpress.com/2014/02/14/para-uma-definicao-do-terrorismo> Acesso em: jan. 2016.

CERRI, Luis F., BONIFÁCIO, Selma de F. O Ensino da História e as Histórias em Quadrinhos: algumas considerações. Disponível em:

<http://www.pucpr.br/eventos/educere/educere2006/anaisEvento/docs/CI-090-TC.pdf > . Acesso em: nov. 2015.

COGGIOLA, Osvaldo. O sentido histórico da Segunda Guerra Mundial. Olho da História, Salvador-Bahia, n. 1, novembro de 1995. Disponível em:

<http://www.oolhodahistoria.ufba.br/01sentid.html>. Acesso em: abr. 2015.

EAGLETON, Terry. A Idéia de Cultura. 2. ed. São Paulo: Unesp, 2011.

FERREIRA, Aurélio Buarque de Holanda. Dicionário Aurélio. Rio de Janeiro: Editora Nova Fronteira, 1988.

FERRO, Marc. A história vigiada. São Paulo: Martins Fontes, 1989.

A manipulação da história no ensino e nos meios de comunicação. São Paulo:

IBRASA, 1983.

FOUCAULT, M. A Ética do Cuidado de Si como Prática da Liberdade. In: MOTTA, M B. da (Org.). Coleção Ditos e Escritos II e V. Rio de Janeiro: Forense Universitária, 2004.

FRONZA, Marcelo. A intersubjetividade e a verdade na aprendizagem histórica de jovens estudantes a partir das histórias em quadrinhos. 2012. Tese (Doutorado) - Universidade Federal do Paraná, Curitiba, 2012.

HYAKUTA, Naoki; SUMOTO, Souichi. Zero Eterno. São Paulo: Editora JBC, 2015. V.1 Zero Eterno. São Paulo: Editora JBC, 2015. V.2 Zero Eterno. São Paulo: Editora JBC, 2015. V. 3

. Zero Eterno. São Paulo: Editora JBC, 2015. V.4

. Zero Eterno. São Paulo: Editora JBC, 2015. V.5 
HOBSBAWM, Eric. Era dos extremos: o breve século XX: 1914-1991. São Paulo:

Companhia das Letras, 1995.

Sobre história. São Paulo: Cia da Letras, 1998.

KONDER, Lenadro. Introdução ao fascismo. São Paulo: Expressão Popular, 1997.

MAIA, Mônica. Historiadores da UFRJ produzem mapa do terrorismo mundial. In: http://www.faperj.br/?id=1042.2.4 Acesso em janeiro de 2015.

MARTON, Fábio. "Kamikazes". Aventuras na história. São Paulo: Editora Abril. n. 119, jun. 2013, p. 28-37.

MOREIRA, Ruy. O que é geografia. São Paulo: Brasiliense, 1990.

OLYMPIO, Guilherme. União Soviética \& USA. Rio de Janeiro: Prado, 1955.

PADROS, Enrique; RIBEIRO, Luis D. T.; GERTZ, René. Segunda guerra mundial. Porto Alegre: Editora Folha da História. 2000.

RODRIGUES, Gabriela. O conflito na Ásia. In: PADROS, Enrique; RIBEIRO, Luis D. T.; GERTZ, René. Segunda guerra mundial. Porto Alegre: Editora Folha da História. 2000, p. 177- 189. 